\title{
Subtropical Cyclogenesis over the Central North Pacific*
}

\author{
Steven J. Caruso and Steven Businger \\ Department of Meteorology, University of Hawaii at Manoa, Honolulu, Hawaii
}

(Manuscript received 15 November 2004, in final form 20 October 2005)

\begin{abstract}
The occurrence of subtropical cyclones over the central North Pacific Ocean has a significant impact on Hawaii's weather and climate. In this study, 70 upper-level lows that formed during the period 1980-2002 are documented. In each case the low became cut off from the polar westerlies south of $30^{\circ} \mathrm{N}$ over the central Pacific, during the Hawaiian cool season (October-April). The objectives of this research are to document the interannual variability in the occurrence of upper-level lows, to chart the locations of their genesis and their tracks, and to investigate the physical mechanisms important in associated surface development. Significant interannual variability in the occurrence of upper-level lows was found, with evidence suggesting the influence of strong El Niño-Southern Oscillation events on the frequency of subtropical cyclogenesis in this region. Of the 70 upper-level lows, 43 were accompanied by surface cyclogenesis and classified as kona lows. Kona low formation is concentrated to the west-northwest of Hawaii, especially during October and November, whereas lows without surface development are concentrated in the area to the east-northeast of Hawaii. Kona low genesis shifts eastward through the cool season, favoring the area to the east-northeast of Hawaii during February and March, consistent with a shift in the climatological position of the trough aloft during the cool season. Consistent with earlier studies, surface deepening is well correlated with positive vorticity advection by the thermal wind. Static stability and advection of low-level moisture are less well correlated to surface deepening. These results suggest that kona low formation, to first order, is a baroclinic instability that originates in the midlatitudes, and that convection and latent-heat release play a secondary role in surface cyclogenesis.
\end{abstract}

\section{Introduction}

The subtropical areas in the central North Pacific Ocean are affected by upper-level lows throughout the year (Palmen 1949; Palmer 1951). During the cool season (October-April), these lows originate as troughs that become cut off from the polar westerlies and are the focal points for surface cyclogenesis. The resulting subtropical cyclones are known as kona lows (Simpson 1952; Ramage 1962; Morrison and Businger 2001). Many leeward areas on the Hawaiian Islands ${ }^{1}$ depend

\footnotetext{
${ }^{1}$ The latitude and longitude ranges of the eight main islands in the Hawaiian chain are $19^{\circ}-22^{\circ} \mathrm{N}$ and $155^{\circ}-160^{\circ} \mathrm{W}$, respectively.

* School of Ocean and Earth Science and Technology Contribution Number 6678.
}

Corresponding author address: Prof. Steven Businger, Dept. of Meteorology, University of Hawaii at Manoa, 2525 Correa Rd., Honolulu, HI 96822.

E-mail: businger@soest.hawaii.edu on kona lows for a significant fraction of their annual rainfall (Daingerfield 1921; Riehl 1949). However, kona lows can also produce extensive damage. The weather-related hazards associated with kona lows include severe thunderstorms, high winds, hail, high surf, heavy rains, flash floods, landslides, blizzard conditions at high elevations, waterspouts, and occasional tornados (Schroeder 1977a,b; Businger et al. 1998). Table 1 describes the five most destructive kona lows that occurred between 1980 and 2002.

Simpson (1952) defined a kona low as a cold-core system of large size, with its strongest circulation in the middle and upper troposphere where it is usually cut off from the polar westerlies. Ramage (1962) narrowed the definition of kona lows to only include closed lows that are cut off from the polar westerlies. Ramage argued that a closed low in a large-amplitude trough that is not cut off from the polar westerlies is essentially no different from a trough without the closed contour, and that such lows are essentially midlatitude cyclones. Ramage's definition has been adopted for this research and refined further to only include storms whose center formed or tracked south of $30^{\circ} \mathrm{N}$, which is often given 
TABLE 1. The five most destructive kona lows occurring from October 1980 to April 2002 . The damage reports $[1$ in. $=25.4 \mathrm{~mm} ; 1$ mile per hour $(\mathrm{mph})=0.4470 \mathrm{~m} \mathrm{~s}^{-1}$ ] are from the NOAA publication Storm Data.

\begin{tabular}{|c|c|c|}
\hline Event date & Associated weather & Tot cost \\
\hline 11-19 Dec 1987 & $\begin{array}{l}\text { Flash flooding } \\
\text { Rainfall of } 12-18 \text { in. on Oahu, Hawaii (first major rainfall in several years for } \\
\text { leeward areas). }\end{array}$ & $>\$ 1$ million \\
\hline 4-5 Nov 1988 & $\begin{array}{l}10 \text { in. of rain } \\
\text { Flooding } \\
\text { High surf } \\
\text { Winds } 40-50 \mathrm{mph} \\
\text { One death }\end{array}$ & $>\$ 1$ million \\
\hline 18-21 Dec 1988 & $\begin{array}{l}\text { Ice and lightning damage } \\
\text { Thunderstorms with hail } \\
\text { Severe wind, snow, and cold resulted in evacuations at Mauna Kea Observatory. }\end{array}$ & $<\$ 50000$ \\
\hline 24-28 Feb 1997 & $\begin{array}{l}\text { High surf } \\
\text { Large hail (13-mm diameter) } \\
\text { Winds }>50 \mathrm{mph} \\
\text { Heavy rains and flooding }\end{array}$ & $>\$ 4$ million \\
\hline 28 Jan-2 Feb 2002 & $\begin{array}{l}\text { Flooding in Maui County } \\
\text { Thunderstorms }\end{array}$ & $>\$ 2.5$ million \\
\hline
\end{tabular}

as the northern extent of the subtropics (Ramage 1995), and includes systems that directly impact Hawaii.

Previous research has shown that storm genesis is closely associated with a north-south-oriented jet streak and enhanced potential vorticity aloft (Fig. 1) (Morrison and Businger 2001). A dry slot in water vapor imagery on the western side of the storm characterizes the location of the jet streak (Fig. 1c). Kona lows have a thermally direct circulation: warm moist air rises in the southeast quadrant of the storm, where the heaviest rainfall and greatest threat for severe weather exist; cool dry air from the north sinks on the western side of the storm, suppressing clouds and convection. The thermal circulation is enhanced by the latent-heat release from the convective cloud bands on the eastern side of the storm. However, the relative importance of latentheat release on surface cyclogenesis is not well understood. Simpson (1952) noted that, on rare occasions, kona lows gain warm-core characteristics, through latent-heat release, and evolve into tropical cyclones.

Kona lows have extended life cycles ( $\sim 5$ days) and operational numerical weather prediction models have difficulty simulating their evolution and erratic tracks. Convective rainbands propagate to the east, while the mature storm tends to move westward. Thus, new mesoscale rainbands form in the clear air to the west of older bands, adding to the challenge of the forecast (Morrison and Businger 2001).

A recent climatology of cyclogenesis over the central North Pacific constructed by Otkin and Martin (2004a) included all storms that moved south of $40^{\circ} \mathrm{N}$, whether or not the low aloft was cut off from the midlatitude westerlies. They adopt Simpson's broader definition of kona lows and distinguish between three types of cyclogenesis: cold-frontal cyclogenesis cyclones, trade wind easterly cyclones, and cold-frontal cyclogenesis/ trade wind easterly cyclones. The three types are distinguished by the degree of baroclinicity in the troposphere.

The purpose of this study is to investigate the climatology (including the tracks, frequencies, and associated surface cyclogenesis) of upper-level lows that form or propagate into the subtropics and that are cut off from the midlatitude westerlies over the central North Pacific. In these cases, surface fronts are absent, and thus these lows fall generally into one of the last two categories of Otkin and Martin (2004a). Not all upperlevel lows develop into kona lows (i.e., develop a surface low) and understanding this distinction is a special focus of this research. Deep convection and rainbands can form in conjunction with upper-level lows without surface development, making them of interest to forecasters monitoring for flash flood potential. However, other weather-related hazards that are associated with kona lows, such as severe thunderstorms, high winds, and high surf are not associated with these weaker systems, making the ability to distinguish between the two systems of significant forecast interest.

\section{Data resources and methods}

Morrison and Businger (2001) showed in their detailed case study of a kona low that the greatest height anomalies and strongest absolute vorticity values occurred at the $250-\mathrm{mb}(1 \mathrm{mb}=1 \mathrm{hPa})$ level. Therefore, the 250-mb level was selected as an appropriate height 

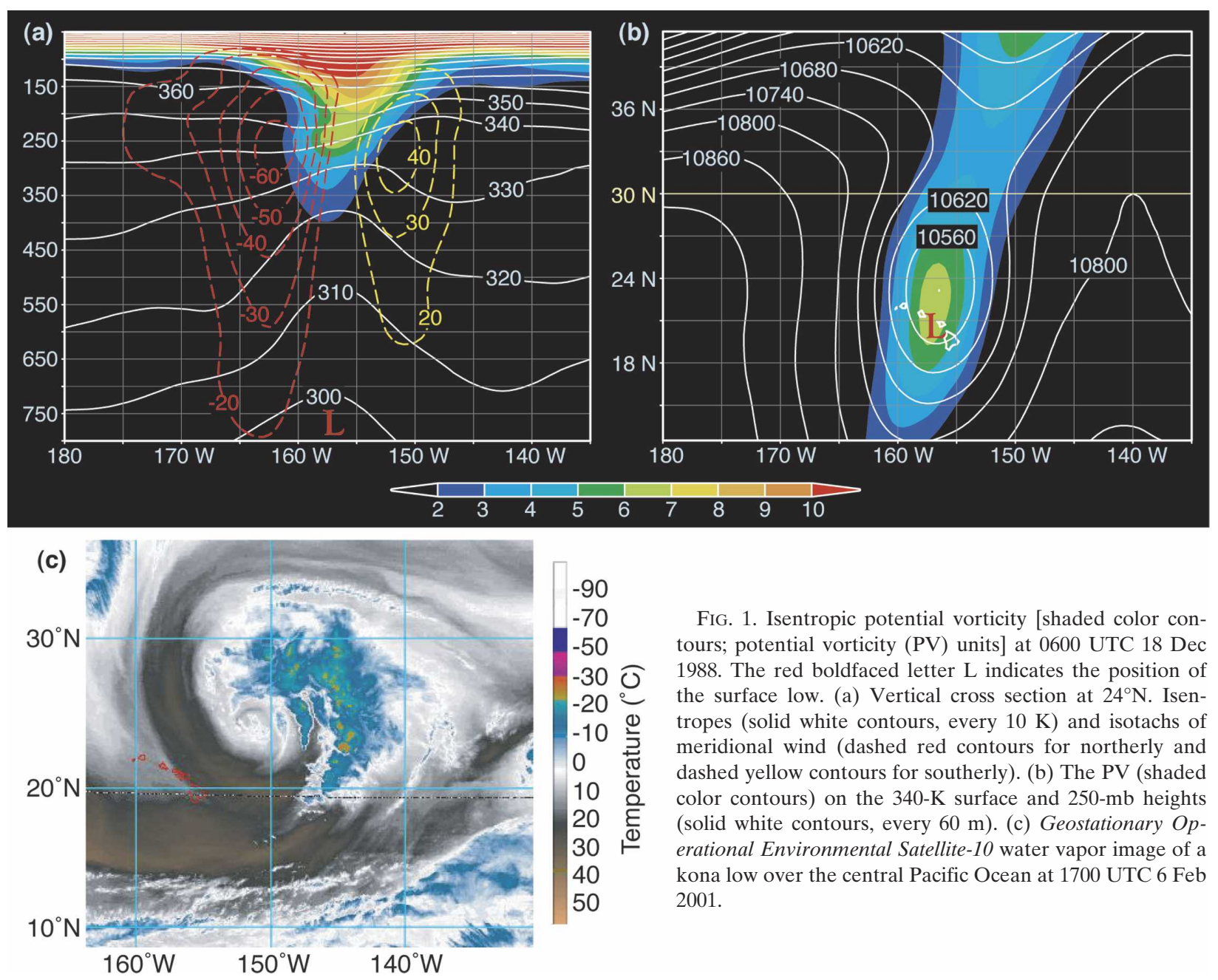

FIG. 1. Isentropic potential vorticity [shaded color contours; potential vorticity (PV) units] at 0600 UTC 18 Dec 1988. The red boldfaced letter $\mathrm{L}$ indicates the position of the surface low. (a) Vertical cross section at $24^{\circ} \mathrm{N}$. Isentropes (solid white contours, every $10 \mathrm{~K}$ ) and isotachs of meridional wind (dashed red contours for northerly and dashed yellow contours for southerly). (b) The PV (shaded color contours) on the $340-\mathrm{K}$ surface and $250-\mathrm{mb}$ heights (solid white contours, every $60 \mathrm{~m}$ ). (c) Geostationary Operational Environmental Satellite-10 water vapor image of a kona low over the central Pacific Ocean at 1700 UTC 6 Feb 2001.

for identifying upper-level lows in this current research. Data from the National Centers for Environmental Prediction-National Center for Atmospheric Research reanalysis project (Kalnay et al. 1996) were used in this study. The reanalysis dataset was completed using a T62 ( 210-km resolution) global spectral model with 28 vertical levels including parameterizations of all major physical processes. Two atmospheric levels in the reanalysis dataset, the $250-\mathrm{mb}$ level and sea level, benefit from a concentration of in situ and remotely sensed data. Data aloft are acquired from in situ measurements from aircraft, rawinsondes, and satellite data over the central Pacific Ocean. Surface data are gathered from standard observations, ships of opportunity, buoys, and satellite-derived quantities (e.g., winds and SST). Reanalysis data are available on a $2.5^{\circ}$ grid at 6 -h intervals. The period of study, October 1980-April 2002, was chosen because of the availability of remotely sensed satellite data incorporated into the reanalysis dataset.

The domain analyzed in this study encompassed $10^{\circ}-45^{\circ} \mathrm{N}$ and $175^{\circ} \mathrm{E}-130^{\circ} \mathrm{W}$. For a low to be included in the study it must meet the following criteria: 1) the upper-level low must remain cut off from the polar westerlies for at least $24 \mathrm{~h}, 2$ ) the upper-level low's center must pass south of $30^{\circ} \mathrm{N}$, and 3 ) the low must occur during the cool season (October-April). The last criterion stems from the observation that few, if any, upper-level cold lows spawn surface cyclones during the remainder of the year. For example, data from the month of September were analyzed and none of the upper-level lows that formed during that month between 1980 and 2002 spawned a surface low. All of the upper-level and surface lows included in this study remained within the study area during their life cycles.

If the 250-mb low produced a closed surface low, it was classified as a kona low system. Otherwise, the event was classified as an upper-level low without surface development. Data were collected from the genesis of a 250-mb low, for example, the first appearance of a closed upper-level low that is cut off from the polar 
westerlies, until the last analysis in which the low is identifiable as a closed-height contour.

\section{Results}

\section{a. Interannual variability}

Careful analysis of the 250-mb height data for the period 1980-2002 reveals 70 upper-level lows that meet the criteria for this study. Of the 70 lows, 43 are classified as kona lows (Table 2) and 27 events as lows without surface development (Table 3). There is significant interannual variability in the number of events per cool season during the $22 \mathrm{yr}$ studied (Fig. 2a). There was an average of approximately three upper-level lows per season, two of which developed into kona lows. The 1990/91 season had a maximum of eight lows, six of which were kona lows. No events occurred in 1980/81 or 1982/83. There were four seasons without kona lows (1980/81, 1982/83, 1984/85, and 1997/98). A maximum of six kona lows occurred during the seasons of 1985/86 and 1991/92. The number of lows without surface development showed similar interannual variability as the kona lows. There was an average of one event per season, and there were seven seasons with no such events occurring (1980/81, 1982/83, 1983/84, 1985/86, 1989/90, 1991/92, and 1993/94). A maximum of three events occurred in four seasons $(1984 / 85,1992 / 93,1998 / 99$, and 1999/2000).

Three strong El Niño events occurred during the years of study: 1982/83, 1991/92, and 1997/98 [National Oceanic and Atmospheric Administration (NOAA)/ Climate Prediction Center)]. In total, only two upperlevel lows occurred during those years, of which only one developed into a kona low. There were also three

TABLE 2. Dates and durations of 43 kona lows occurring in the central North Pacific during the study period (1980-2002).

\begin{tabular}{lcl}
\hline \multicolumn{3}{c}{ Occurrence of kona lows } \\
\hline 3-7 Oct 1981 & 8-13 Oct 1989 & 30 Oct-5 Nov 1994 \\
20-24 Dec 1981 & 31 Oct-3 Nov 1989 & 8-13 Nov 1994 \\
18-22 Nov 1983 & 3-8 Nov 1989 & 16-19 Oct 1996 \\
15-19 Oct 1985 & 9-13 Dec 1989 & 2-7 Nov 1996 \\
29 Oct-2 Nov 1985 & 24-29 Jan 1990 & 24-28 Feb 1997 \\
2-6 Nov 1985 & 27-31 Mar 1990 & 6-10 Mar 1999 \\
3-8 Nov 1985 & 2-6 Oct 1990 & 18-24 Oct 1999 \\
26-30 Nov 1985 & 8-12 Oct 1990 & 26-30 Nov 1999 \\
29 Dec-2 Jan 1986 & 16-20 Oct 1990 & 27 Dec-1 Jan 2000 \\
11-16 Nov 1986 & 20-25 Oct 1990 & 3-7 Feb 2001 \\
10-16 Dec 1987 & 12-15 Nov 1990 & 24-28 Oct 2001 \\
16-20 Dec 1987 & 23-28 Nov 1990 & 26-30 Nov 2001 \\
3-8 Nov 1988 & 13-16 Nov 1991 & 28 Jan-3 Feb 2002 \\
17-21 Dec 1988 & 5-11 Oct 1992 & \\
25 Feb-2 Mar 1989 & 7-12 Nov 1993 \\
\hline
\end{tabular}

TABLE 3. Dates and durations of 27 upper-level systems without surface lows during the study period (1980-2002).

\begin{tabular}{lll}
\hline \hline \multicolumn{3}{c}{ Occurrence of upper-level lows } \\
\hline 24-26 Nov 1981 & 1-4 Dec 1990 & 25-29 Dec 1997 \\
28 Oct-1 Nov 1984 & 7-11 Nov 1992 & 10-14 Oct 1998 \\
23-27 Feb 1985 & 26-30 Nov 1992 & 2-5 Nov 1999 \\
1-4 Mar 1985 & 10-14 Dec 1992 & 4-8 Dec 1999 \\
15-20 Nov 1986 & 1-7 Oct 1994 & 13-20 Dec 1999 \\
13-16 Oct 1987 & 19-22 Oct 1994 & 5-9 Jan 1999 \\
19-22 Oct 1988 & 12-16 Jan 1996 & 12-16 Jan 1999 \\
18-22 Nov 1988 & 20-26 Oct 1996 & 14-18 Mar 2001 \\
8-14 Oct 1990 & 18-23 Dec 1996 & 11-14 Dec 2001 \\
\hline
\end{tabular}

seasons with moderate to strong La Niña events: 1988/ 89, 1998/99, and 1999/2000. A total of 15 upper lows, seven of which were kona lows, developed during those years. On average, five upper-level lows with two developing into kona lows, occurred during a moderate to strong La Niña event. These statistics, though not conclusive, suggest a modulation of the frequency of kona low formation in the central North Pacific by the
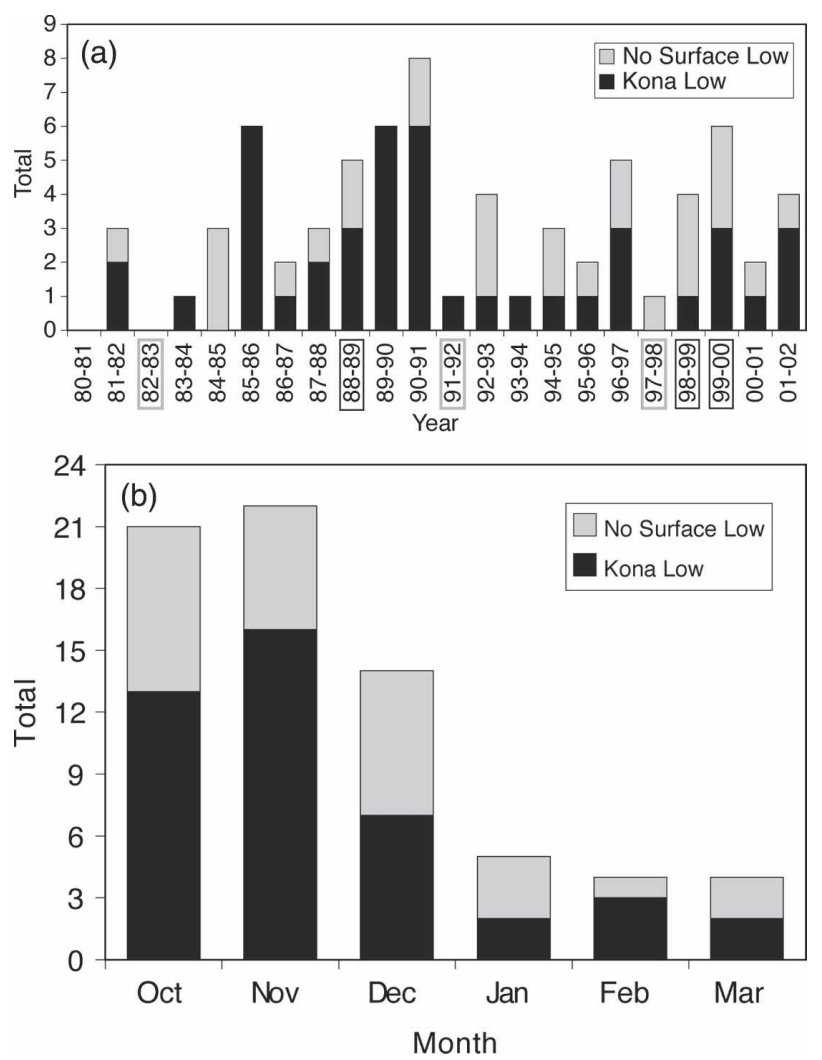

FIG. 2. The number of upper-level lows by (a) year and (b) month for the period 1980-2002. The years denote winter seasons, from Oct to Apr. The years outlined in gray boxes indicate strong El Niño events and the years outlined in black boxes indicate moderate to strong La Niña events. 

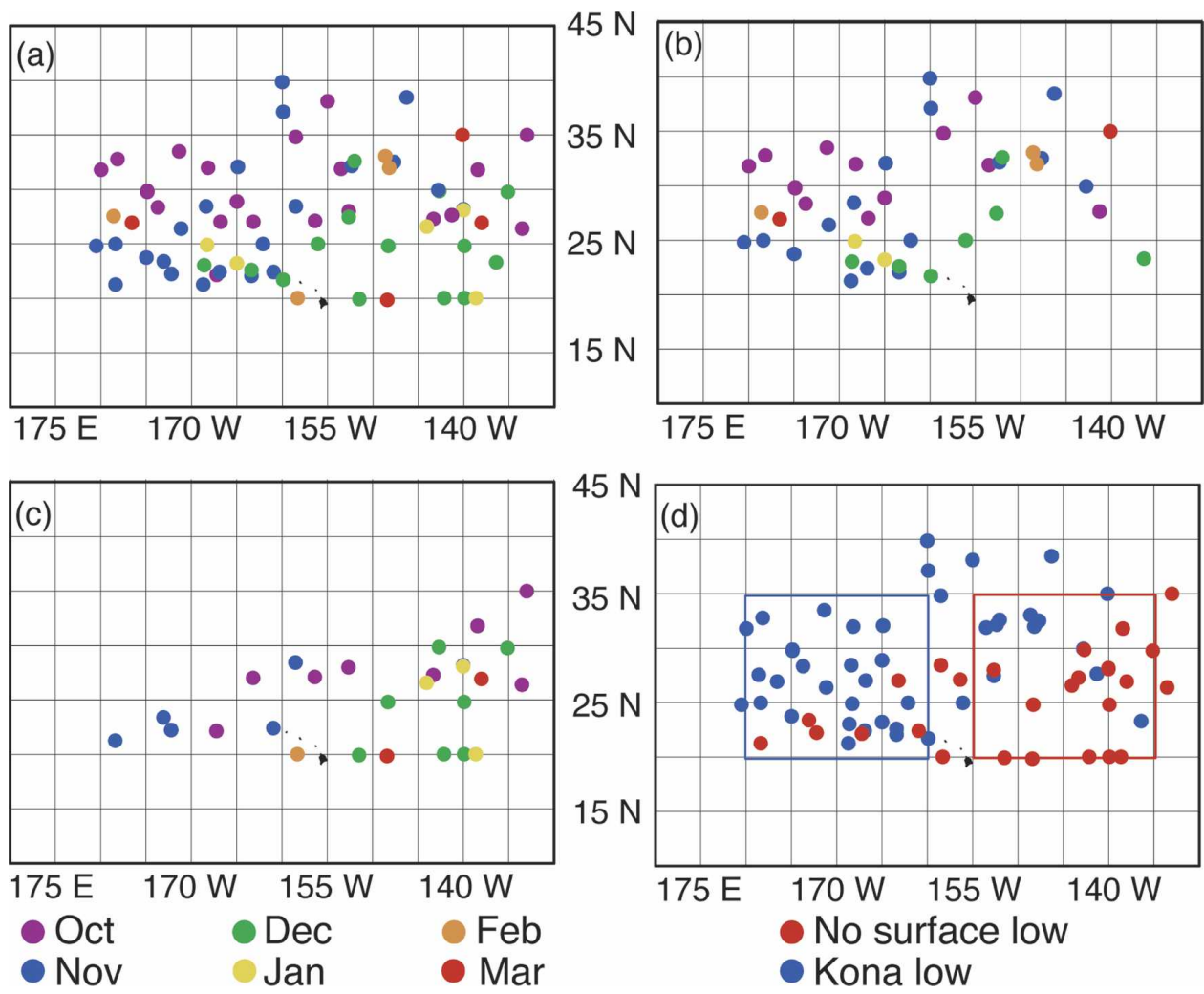

FIG. 3. Location and month of genesis of upper-level lows during the period of study (1980-2002) for (a) all upper-level lows, (b) kona lows, and (c) upper-level lows without surface lows. (d) Locations of all upper-level lows where blue indicates kona lows, and red indicates upper-level lows without surface development. Sixty percent of the kona lows formed within the blue box, whereas $60 \%$ of the lows without surface development formed within the red box.

strongest El Niño-Southern Oscillation (ENSO) events.

The development of upper-level lows and kona lows is favored during the autumn months of October and November (Fig. 2b). Twenty-nine of the 43 kona lows $(\sim 67 \%)$ formed during these two months. There were $\sim 15$ kona lows per month in October and November, with an average of approximately four kona lows occurring in each of the remaining months of DecemberMarch. The total number of upper-level lows and kona lows peaked during the month of November with 22 total events (16 kona lows).

\section{b. Location of storm genesis}

The location of low genesis was determined by identifying where the upper-level low first became cut off from the polar westerlies. Upper-level lows preferentially form in the area to the west-northwest of the Hawaiian Islands during the months of October and November, with an eastward shift in the location of genesis as the season progresses (Fig. 3a). Conse- quently, the majority of the kona lows also developed to the west of the Hawaiian Islands during the months of October and November (Fig. 3b), and there is a similar eastward shift in the genesis location for kona lows during the months of December and January. However, there were only five kona lows that formed in February and March, and those storms either formed well to the northeast or the northwest of the Hawaiian Islands.

An eastward progression in the location of upperlevel lows without surface development is also apparent, with the exception of one low that developed just south of Oahu during the month of February (Fig. 3c).

There is a clear distinction in the favored genesis locations of kona lows and lows without surface development; $60 \%$ of the kona lows formed to the westnorthwest of the Hawaiian Islands, and $60 \%$ of the lows without surface development formed to the eastnortheast of the islands (Fig. 3d). The cause of this difference is a reduction in the strength of the upperlevel cyclonic thermal vorticity advection (CTVA) and a reduction in the meridional component of the winds 

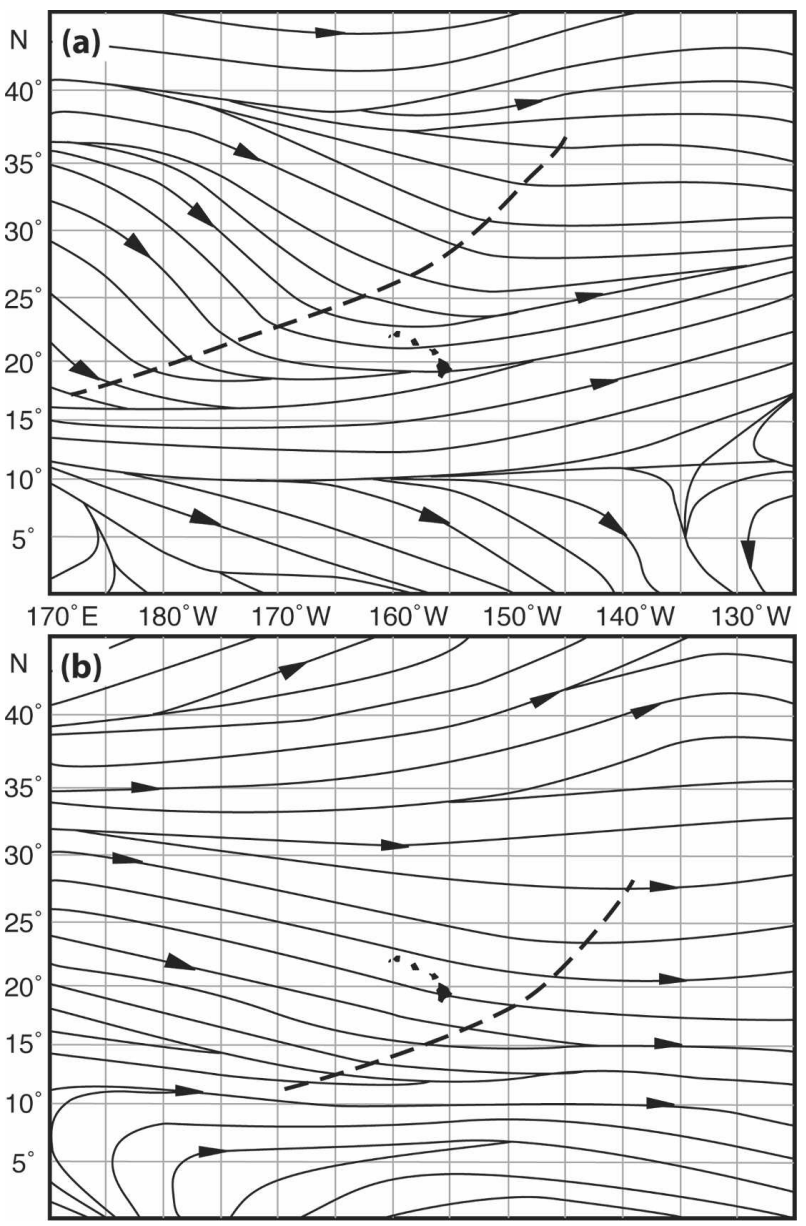

FIG. 4. Average 200-mb streamlines for (a) Oct and (b) Feb (after Sadler 1975).

aloft later in the season. These changes occur along with a shift in the preferred location of the upper-level trough in the climatology (Fig. 4) (Sadler 1975).

\section{c. Storm tracks}

The area to the west of the Hawaiian Islands is the favored location for passage of upper-level lows (Fig. $5 a)$. Over $75 \%$ of the kona upper-level lows tracked southward to the west of Hawaii. Also, 39 of the 43 kona upper-level lows had some westward motion during their lifetime. Upper-level lows without surface development tracked southward, predominately to the east of the Hawaiian Islands (Fig. 5b). The motion of these lows is similar to that of the kona lows, with a majority of the lows exhibiting a westward component to their motion.

The tracks were also determined for the kona surface lows (Fig. 6a). In some events, the upper-level low formed before there was a closed surface low. Comparison of the upper-level and surface tracks revealed that some of the kona lows became decoupled during the spindown phase (not shown). While a storm is weakening, the upper-level low sometimes separates from the surface low and moves in an entirely different direction. Kona lows tend to move in a southerly direction while deepening (e.g., Fig. 6b). Once the storms reach their lowest sea level pressure (mature stage), the tracks tend to curve to the west and eventually to the northwest.

\section{Surface development}

Previous studies suggest that baroclinic instability is the primary physical mechanism for cyclogenesis in kona lows (Simpson 1952; Ramage 1962; Morrison and Businger 2001; Otkin and Martin 2004a). Two fundamental questions are investigated in this section: 1) how does surface deepening respond to upper-level forcing, and 2) is there a role for organized convection and latent heating in the development of a surface cyclone that is distinct from the large-scale dynamic forcing provided by moist baroclinicity (e.g., Mak 1982) in the system?

Implicit in the first question is the relevant forecast issue of what range of surface deepening can be anticipated for a given level of large-scale forcing. The second question stems from the observation that hurricane-like cores sometimes develop in storms associated with strong upper-level lows at higher latitudes, such as polar lows (Businger and Baik 1991) and occluded cyclones (Bosart 1981). In the subtropics, where dewpoint temperatures are relatively high near the surface, it is reasonable to suppose that a signal from such a feature might appear in a statistical analysis (e.g., Roebber 1984).

The average life span of a kona low was five days (Fig. 7), with an average deepening of 6-mb during a 60-h intensification period. The lowest average minimum pressure was $\sim 1006 \mathrm{mb}$. However, two kona lows deepened to less than $997 \mathrm{mb}$, which is significantly lower than the average. Upper-level lows without surface development had relatively high values of minimum sea level pressure, averaging $1014 \mathrm{mb}$.

To address the questions above, it is useful first to diagnose the impact of baroclinicity through quasigeostrophic forcing. A convenient form of the quasigeostrophic omega equation is available to assess the synoptic-scale vertical velocity in synoptic systems, which is proportional to surface deepening (Sutcliffe 1947; Trenberth 1978): 
(a)

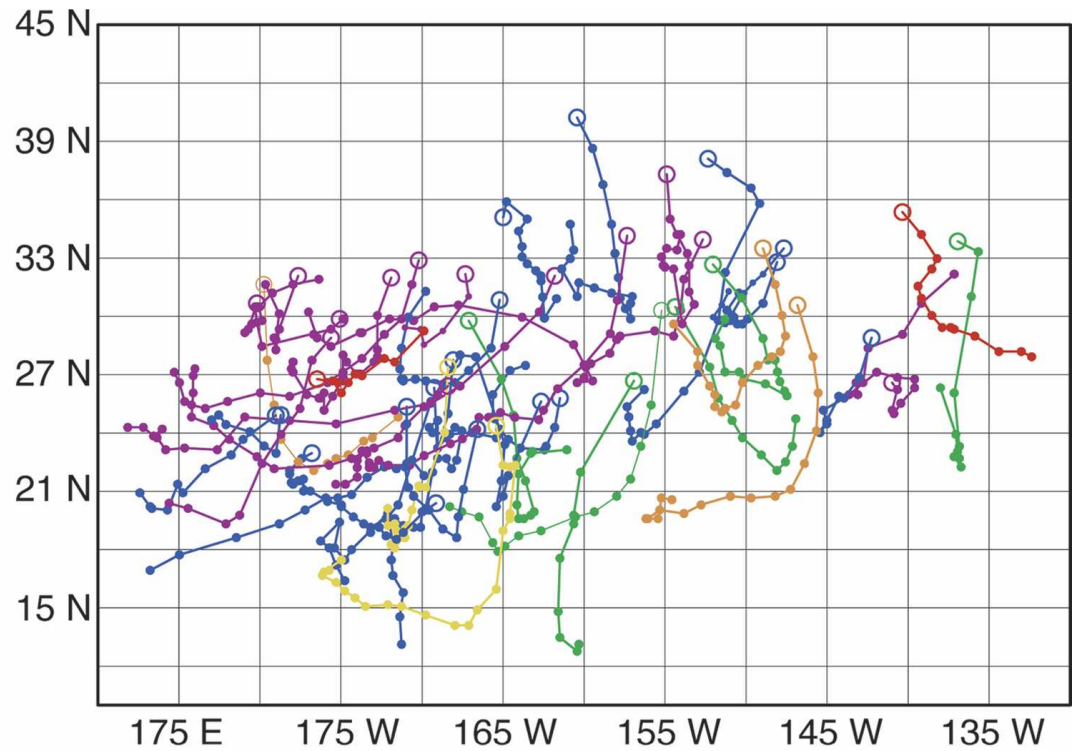

(b)

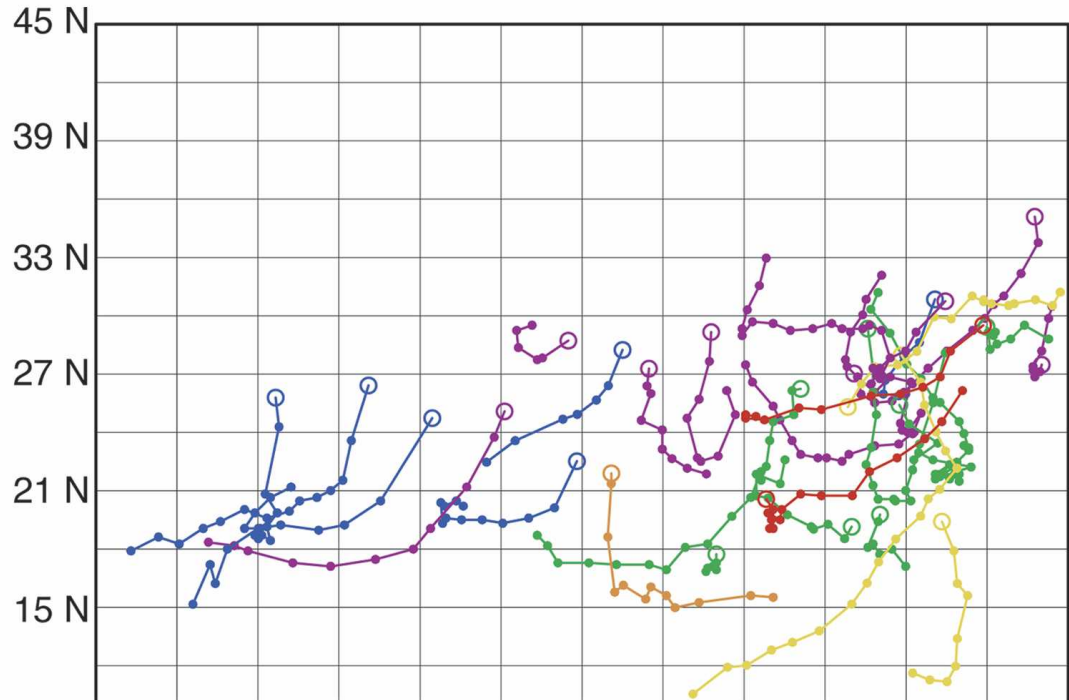

- October

- November

\section{December} January

\section{February}

- March

FIG. 5. Tracks of upper-level low centers at $250 \mathrm{mb}$, with locations (dots) at 6-h intervals. Open circles mark the initial position. Tracks end at last position where a low was identifiable through a closed-height contour. (a) Tracks of kona lows and (b) without surface lows.

$\left(\sigma \nabla^{2}+f_{0}^{2} \frac{\partial^{2}}{\partial p^{2}}\right) \omega=2 f_{0} \frac{\partial V_{g}}{\partial p} \cdot\left(\nabla \frac{1}{f_{0}} \nabla^{2} \phi\right)$

$+($ Deformation Terms),

(1)

where $\sigma$ is the static stability parameter, $\nabla$ is the twodimensional gradient operator, $f_{0}$ is the Coriolis parameter, $p$ is pressure, $\omega$ is vertical motion, $V_{g}$ is the geostrophic wind, and $\phi$ is the geopotential height. The term on the left-hand side represents the threedimensional Laplacian of $\omega$, the first term on the righthand side is the advection of vorticity by the thermal wind, and the second term on the right hand side is the deformation term. The Sutcliffe-Trenberth approach assumes that the deformation terms are relatively small and can be neglected. The advantage of this approach is that synoptic-scale vertical motion in the middle troposphere is approximately proportional to vorticity advection by the thermal wind and can be assessed from a 


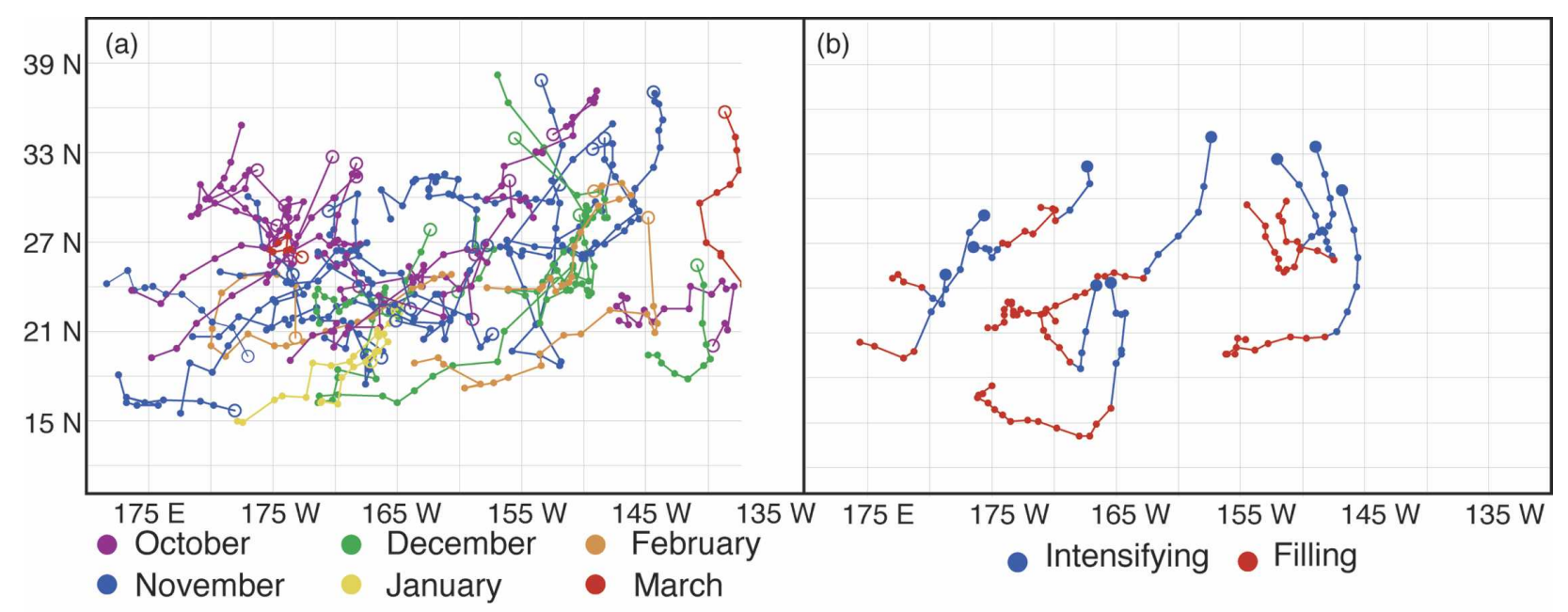

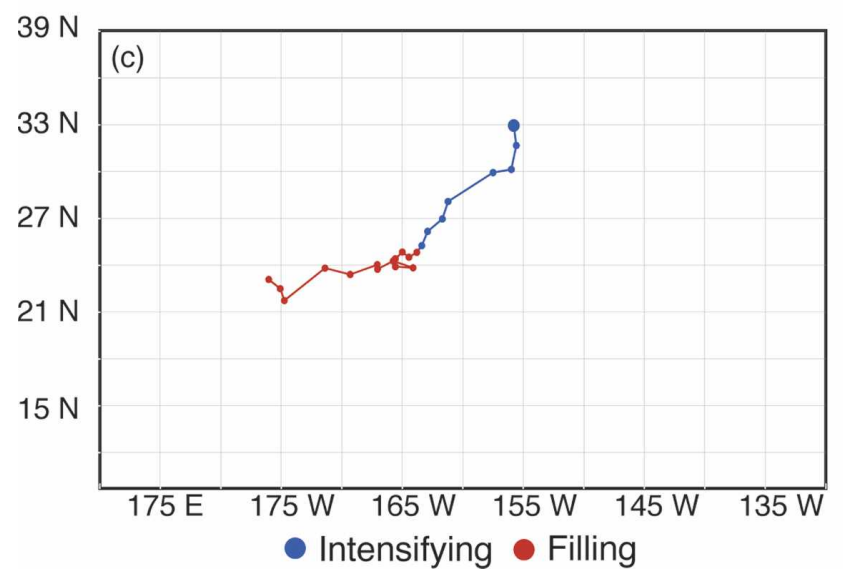

single map. Martin (1998) demonstrates that the deformation terms are relatively small in the middle troposphere during the early stages of cyclogenesis. However, they become more important during the later (occluded/dissipating) stages. In this study, the focus is primarily on the cyclogenesis phase of kona lows. Therefore, the Sutcliffe-Trenberth approach is used to obtain a maximum positive vorticity advection by the thermal wind, alternatively, CTVA, for each map time. The maximum values of CTVA may be slightly underestimated in the later stages of the kona low life cycle using the Sutcliffe-Trenberth approach (Martin 1998). However, this does not alter the overall conclusions of the analysis.

A characteristic of kona lows is that the CTVA maximum is located to the west of the surface low, which promotes the development of new convection to the west of older convective cloud bands (Fig. 8) (Morrison and Businger 2001). During the mature and dissipating stages of the kona low, new deep convection may contribute to the westward propagation of the surface low
FIG. 6. Tracks of (a) surface low centers and (b) a subsample of kona lows at the 250-mb level occurring between 1996 and 2002, with locations (dots) at 6-h intervals. Blue tracks indicate that the associated surface lows are deepening and red tracks indicate that the surface lows are filling. (c) Average surface track for all kona lows. through the hydrostatic impact of latent heating on sea level pressure. The maximum CTVA value was calculated every $6 \mathrm{~h}$ for the life cycle of the 70 events (Fig. 9). At the time of the greatest surface deepening on average, there is a distinct CTVA maximum in the average for the 43 kona low cases. The maximum average value of CTVA is $\sim 5.2 \times 10^{-10} \mathrm{~s}^{-2}$. Average values of CTVA continue to decline for the rest of the lows' lifetimes. The time series of average CTVA for lows without surface-low development does not show a distinct early maximum (Fig. 9). The average value of maximum CTVA ranges from $\sim 2.5$ to $\sim 3.5 \times 10^{-10} \mathrm{~s}^{-2}$ at all times for the lows without surface development.

\section{Statistical analysis}

In this section, the range of surface deepening for a given level of large-scale forcing is explored. In addition, the presence or absence of signals in the deepening rate associated with convective activity is analyzed. Correlation coefficients were calculated for select variables to investigate their relationship with the deepen- 


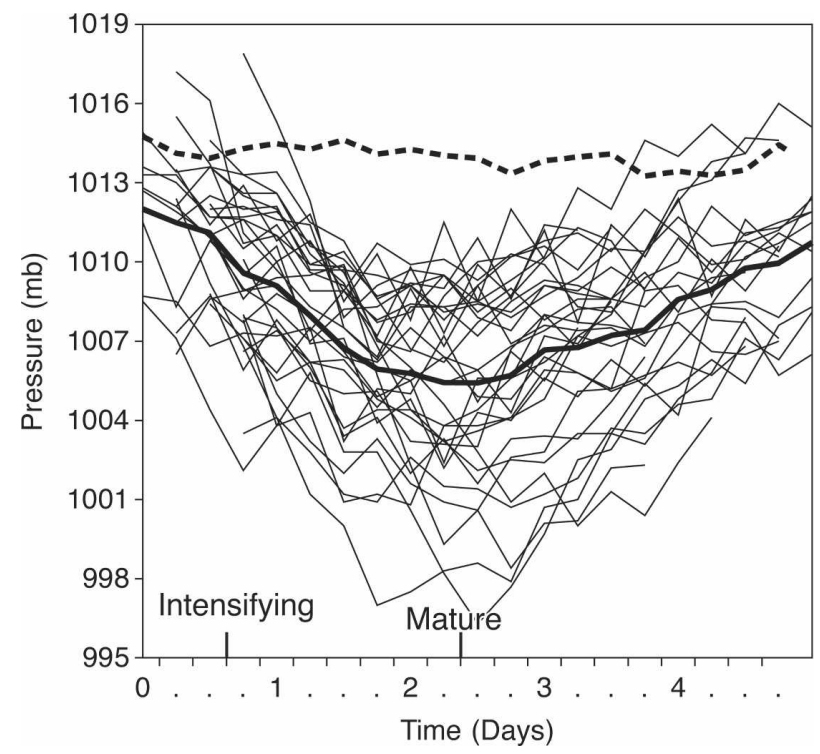

FIG. 7. Time series of sea level central pressure for kona lows. The boldface black line is the average pressure trace of all kona lows. The boldface dashed line is the average surface pressure trace for cases without surface lows.

ing rate. The data points were chosen at the time of the most rapid sea level pressure falls for all variables, for example, at the midpoint of the maximum 12-h pressure fall. The following equation was used to calculate the correlation coefficient.

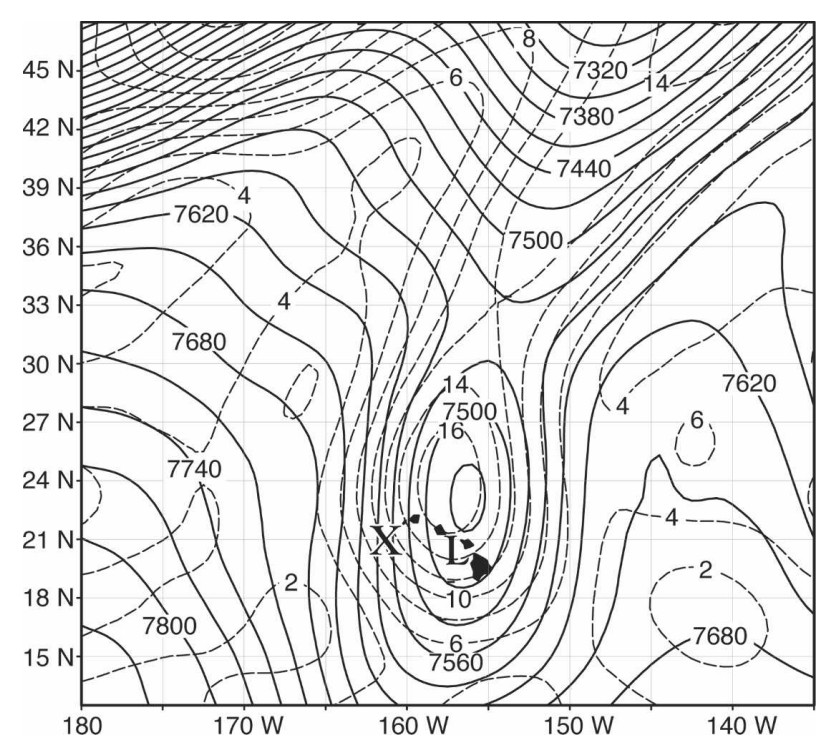

FIG. 8. Absolute vorticity at $500 \mathrm{mb}$ (dashed lines, every $2 \times$ $10^{-5} \mathrm{~s}^{-1}$ ), 700-250-mb thickness (solid lines, every $30 \mathrm{~m}$ ) for 0600 UTC 18 Dec 1988. The capital X indicates location of maximum value of CTVA and the capital L indicates the position of the surface low.

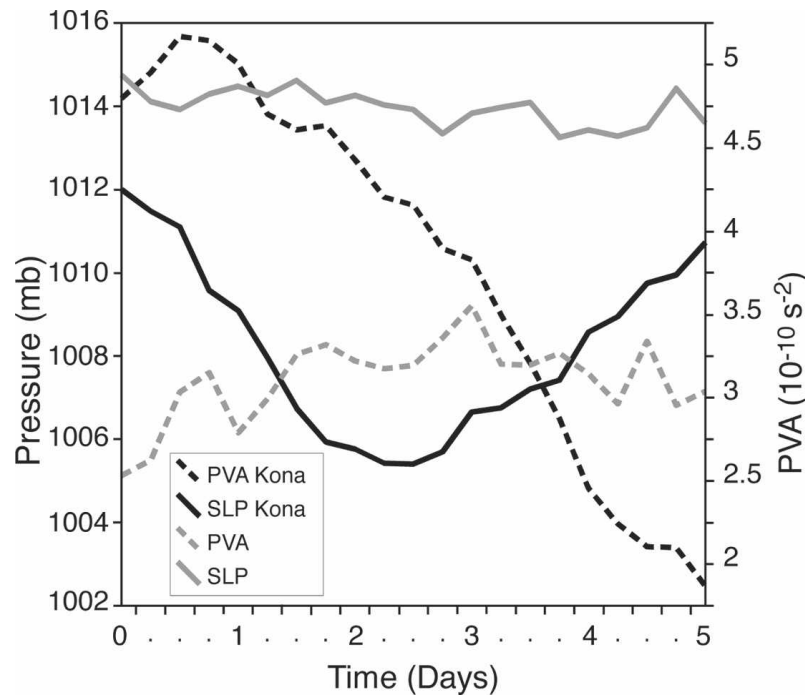

FIG. 9. Time series of average CTVA (dashed lines) and average surface pressure (solid lines) for kona lows (black lines) and lows without surface lows (gray lines).

$$
r=\frac{\sum_{m} \sum_{n}\left(\mathbf{A}_{m n}-\overline{\mathbf{A}}\right)\left(\mathbf{B}_{m n}-\overline{\mathbf{B}}\right)}{\left[\left(\sum_{m} \sum_{n}\left(\mathbf{A}_{m n}-\overline{\mathbf{A}}\right)^{2}\right)\left(\sum_{m} \sum_{n}\left(\mathbf{B}_{m n}-\overline{\mathbf{B}}\right)^{2}\right)\right](1 / 2)},
$$

where $\mathbf{A}$ and $\mathbf{B}$ are matrices of the same size, $m$ and $n$ are the dimensions of the matrices, and $r$ is the correlation coefficient. Quenouille's (1952) method of reducing the effective number of degrees of freedom due to autocorrelation was used to test the significance of the correlation coefficient values.

Not surprisingly, CTVA shows a strong correlation with surface deepening (correlation coefficient of -0.72 ; see Fig. 10a). The nearly linear relationship between the surface deepening and the maximum CTVA shown in Fig. 10a can serve as a useful guide for forecasters, allowing them to anticipate the deepening rate of kona lows, given accurate forecast or observed values of maximum CTVA.

As proxies for convective latent-heat release, lowlevel advection of moisture and the best lifted index (BLI) are analyzed. Fujita et al. (1970) used the BLI as a measure of how conducive the atmosphere is for deep convection. Similarly, low-level moisture advection has been linked to convective rainfall (e.g., Junker et al. 1999). Areas of enhanced low-level moisture advection and negative values of BLI have been shown to coincide with areas of deep convection in kona lows (Morrison and Businger 2001).

The absence of a correlation between low-level 


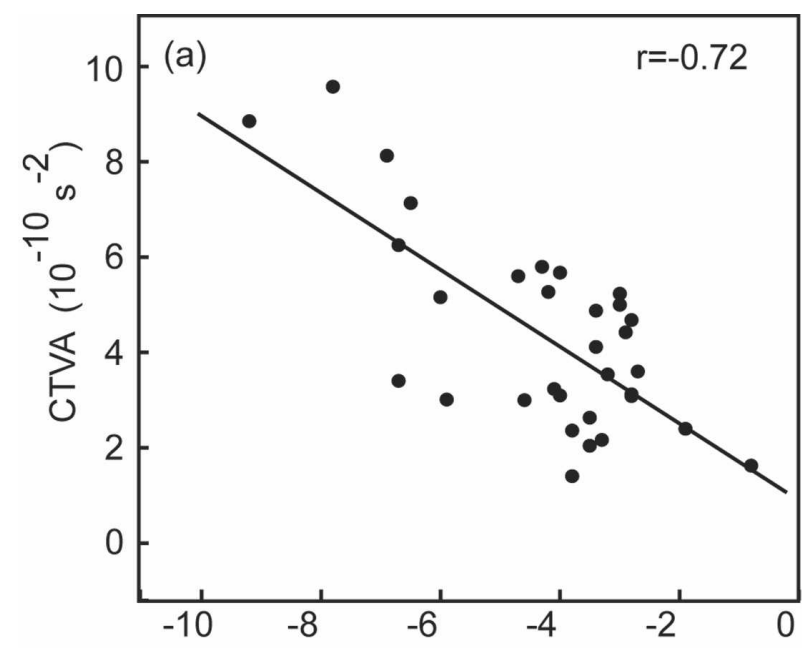

24-Hour Surface Pressure Change (mb)
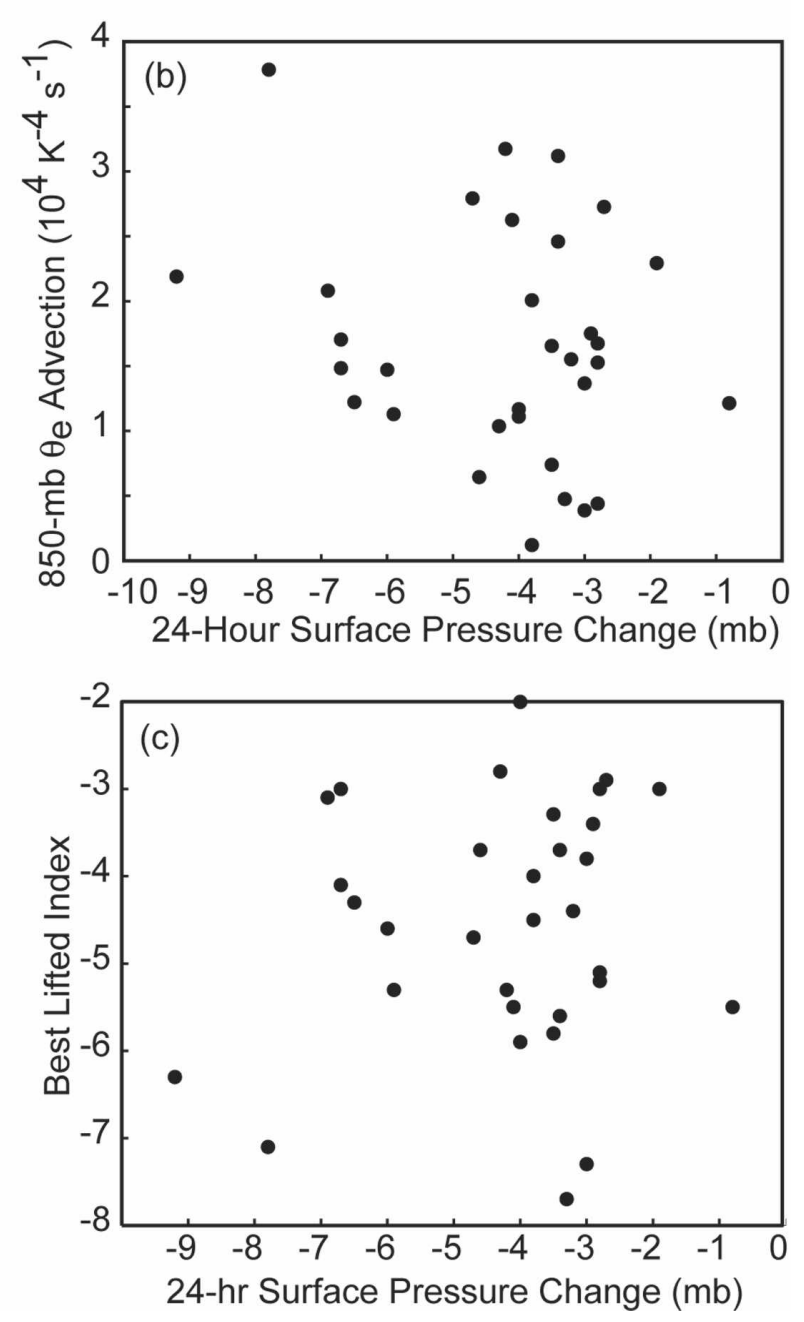

FIG. 10. Scatter diagrams of (a) CTVA vs 24-h surface pressure change, (b) 850-mb $\theta_{e}$ advection $\left(\times 10^{4} \mathrm{~K}^{-4} \mathrm{~s}^{-1}\right)$ vs 24-h surface pressure change, and (c) BLI vs 24-h surface pressure change. equivalent potential temperature $\theta_{e}$ advection and surface deepening is noteworthy (Fig. 10b). Similarly, there is little correlation between BLI and surface deepening (Fig. 10c). These results suggest that convection and latent-heat release play an important but secondary role in surface cyclogenesis, a point that will be returned to in the discussion part of section 5 .

\section{Conclusions and discussion}

The occurrence of subtropical cyclones over the central North Pacific Ocean has a significant impact on Hawaii's weather and climate. In this study, 70 upperlevel lows that formed during the period 1980-2002 are documented. In each case, the low became cut off from the polar westerlies south of $30^{\circ} \mathrm{N}$ over the central Pacific, during the Hawaiian cool season (October-April). The objectives of this research are to document the interannual variability in occurrence, the locations of genesis, and the tracks, and to investigate physical mechanisms important in associated surface development. Principal conclusions of the research are summarized as follows.

- Forty-three of the 70 upper-level systems developed into kona lows, an average of $\sim 2$ per cool season.

- Twenty-seven of the 70 upper-level systems showed no surface development, an average of $\sim 1$ per cool season.

- Significant interannual variability for all upper-level lows was found. Frequency statistics suggest that strong ENSO events influence the occurrence of upper-level and kona lows in the central North Pacific.

- Kona low formation is concentrated to the westnorthwest of Hawaii, especially during October and November, whereas lows without surface development are concentrated in the area to the eastnortheast of Hawaii.

- The location of storm genesis progresses eastward through the cool season, consistent with an eastward shift in the climatological position of the trough aloft during the cool season.

- Kona low life cycles average five days, reaching maturity in $\sim 60 \mathrm{~h}$, with a 6-mb drop in sea level pressure on average.

- During kona low intensification, the storm motion is predominately southward. Following maturity, the storm motion becomes more westerly; 39 of the 43 kona lows had some westward motion.

- A CTVA maximum is associated with the period of greatest surface deepening. Lows without surface development were not accompanied by high values of CTVA. Statistical analysis shows that surface deepening is strongly correlated with CTVA. 
- As proxies for convective latent-heat release, lowlevel moisture advection and BLI show little correlation with surface deepening.

Kona lows show a pattern of significant interannual variability with the suggestion of a modulation by ENSO. Previous research has suggested that rainfall deficits in the Hawaiian Islands during the cool season are associated with El Niño events (Chu 1995). An enhanced Hadley circulation develops near the date line as a result of the eastward shift of the warm pool toward the equatorial central Pacific and increased convection with strong ascending motion just north of the equator. The Hadley circulation and the subtropical jet stream both support upper-level convergence and subsidence near the Hawaiian Islands, suppressing cyclogenesis and contributing to the dry conditions, as part of a larger Pacific-North America pattern (Horel and Wallace 1981). Otkin and Martin (2004b) show that cyclogenesis is favored during periods of a weaker, zonally retracted Asian jet stream, which is a characteristic of strong La Niña events. The retracted Asian jet results in a favorable location for the southward-directed ageostrophic flow in the jet exit region to contribute to the formation of a north-south-oriented jet streak shown to be associated with kona low formation (Morrison and Businger 2001). Otkin and Martin (2004a) did a linear statistical analysis of ENSO (as measured by the multivariate ENSO index) and the frequency of their kona storms and found little evidence of a correlation. It is known that the impact of El Niño is geographically sensitive. Therefore, the difference between their result and that presented here is likely due to the substantially larger geographic window used in their study $\left(10^{\circ}-40^{\circ} \mathrm{N}\right.$ and $\left.130^{\circ} \mathrm{W}-160^{\circ} \mathrm{E}\right)$. The $10-\mathrm{yr}$ period of their statistical study is short when compared with the typical ENSO cycle of $4 \mathrm{yr}$, impacting the reliability of their results (Panofsky and Brier 1968).

An upper-level trough in a long-term height climatology reflects an area favored for cyclogenesis. A 30-yr climatology of 200-mb heights shows that an upperlevel trough in the mean height field is located northwest of the Hawaiian Islands during the month of October (Fig. 4a). Upper-level lows that deepen and cut off from the westerlies during the autumn contribute to the location and strength of the mean trough. In February, a weak mean trough is only just discernable to the east of the Hawaiian Islands (Fig. 4b), consistent with the reduced frequency of lows at this time. The eastward shift of the mean 200-mb trough is mirrored by the eastward progression of cyclogenesis.

The distribution of genesis locations and the tracks of the lows in this climatology have implications for fore- casters. In the autumn, kona lows tend to be stronger and preferentially track to the west of Hawaii, placing the convectively active part of the storm during the mature phase near or over Hawaii. The potential for severe thunderstorms to impact Hawaii is greatest from these storms. Conversely in the winter, lows on average are weaker and form to the east of Hawaii, with a tendency for the weakening or dissipating stage of the low to track westward across the islands. High surf along northeast shores is a recurring hazard from these storms.

The vorticity centers of kona lows aloft and at the surface become vertically stacked during their mature stages and are nearly equivalent barotropic (Morrison and Businger 2001). The track results presented here are consistent with the view that a weakening kona low behaves as an equivalent-barotropic vortex. Since the vortex at this stage is isolated from the westerlies to the north, the theory used to explain tropical cyclone motion may be applied to kona low motion. The beta-drift model predicts that the motion of a barotropic vortex is controlled by the advection of planetary vorticity. Higher planetary vorticity is advected south on the western side of the vortex, with lower planetary vorticity advected north on the eastern side. This results in the formation of counter-rotating gyres or beta gyres that are responsible for a secondary asymmetric circulation and northwestward propagation (Wang and Li 1992; Li and Wang 1994). Morrison and Businger (2001) suggest that a Rossby wave dispersion approach provides a reasonable prediction of the zonal component of kona low motion. Westward motion in the latter stages of the kona low may reflect a steering influence of a background northeast trade-wind flow.

Simpson (1952) analyzed $20 \mathrm{yr}$ of data and found that 76 kona lows occurred. That total is almost double the number of kona lows (43) found in this study, which included $22 \mathrm{yr}$ of data. The difference may reflect a change in the strength of the Hadley circulation over the central equatorial Pacific associated with a change in the climate (Hou 1998; Dai et al. 2001). Alternatively, the difference may be due to the lack of upperlevel data during Simpson's study and his inclusion of lows not completely cut off from the polar westerlies. Determining the winds at $250 \mathrm{mb}$ over the Pacific Ocean was difficult before the availability of satellite and aircraft data. Upper-level lows that do not become cut off from the polar westerlies are midlatitude frontal cyclones forming at lower latitudes and as such are distinct from kona lows, as defined in this study. The criteria of including only storms that became cut off from the midlatitude westerlies was also used in the broader 
study of subtropical cyclogenesis undertaken by Otkin and Martin (2004a,b).

A specific focus of this research is an investigation of the difference between upper-level lows with surface cyclogenesis and upper-level lows without surface development. Maximum CTVA was the variable most closely related to surface deepening (e.g., Figs. 9 and 10a). This finding is consistent with baroclinic theory (Sutcliffe 1947; Farrell 1984) and supports previous studies showing that kona lows are manifestations of baroclinic instability (Morrison and Businger 2001; Martin and Otkin 2004). Since global models show the most skill at forecasting changes in the free-atmospheric height field, forecasters can use model output CTVA as a guide for anticipating the strength of surface cyclogenesis (e.g., Fig. 10a). A cutoff upper-level low with a high value of CTVA (above $4 \times 10^{-10} \mathrm{~s}^{-2}$ ) would be more likely to develop a surface cyclone than a low without high CTVA (below $3 \times 10^{-10} \mathrm{~s}^{-2}$ ). Additionally, lows developing to the northwest of Hawaii during the favorable autumn season should receive special attention.

Positive $\theta_{e}$ advection at low levels contributes to the destabilization of the troposphere and coincides with areas of deep convection in kona lows (Morrison and Businger 2001). Latent heating associated with deep convection results hydrostatically in a decrease in sea level pressure. However, static stability (BLI) and advection of low-level moisture are found to correlate poorly with surface deepening. These results suggest that to first order, upper-level forcing drives kona low formation. Baroclinic instability in the middle and upper troposphere organizes the convection and latentheat release, which play a secondary role in surface cyclogenesis. However, that is not to suggest that latent-heat release is not a critical factor in cyclogenesis. Numerous studies have shown its importance in baroclinic systems (e.g., Gall 1976; Mak 1982; Martin and Otkin 2004). Rather, the results suggest that the availability of low-level moisture is not a limiting factor in the surface development in kona lows. This finding may not be so surprising when one considers that the marine boundary layer over the subtropical ocean contains on average $\sim 25 \mathrm{~mm}$ of precipitable water (Foster et al. 2003), which provides ample moisture for deep convection when dynamically lifted in a developing kona low.

The subtropical central North Pacific Ocean was the focus area of this research. However, subtropical cyclones are not limited to the Pacific Ocean basin. Similar storms have been documented in the Atlantic (Simpson 1952; Hebert and Poteat 1975). It is suggested that some of the results presented here could be generalized to Atlantic subtropical cyclones.
Acknowledgments. The authors thank Jonathan Martin for his constructive comments on an initial draft of the manuscript. We are also grateful to Dr. Tom Schroeder, Dr. Anders Daniels, and Robert Farrell (lead forecaster, NWSFO HFO) for helpful suggestions made during the course of this work. Comments from three anonymous reviewers resulted in significant improvements in the final manuscript. This research was supported by the National Science Foundation under Grant ATM99-09011 and NOAA under Grant NA17EC1105.

\section{REFERENCES}

Bosart, L. F., 1981: The Presidents' Day snowstorm of 18-19 February 1979: A subsynoptic-scale event. Mon. Wea. Rev., 109, 1542-1566.

Businger, S., and J. J. Baik, 1991: An arctic hurricane over the Bering Sea. Mon. Wea. Rev., 119, 2293-2322.

, T. Birchird Jr., K. Kodama, P. A. Jendrowski, and J. Wang, 1998: A bow echo and severe weather associated with a kona low in Hawaii. Wea. Forecasting, 13, 576-591.

Chu, P.-S., 1995: Hawaii rainfall anomalies and El Niño. J. Climate, 8, 1697-1703.

Dai, A., T. M. L. Wigley, B. A. Boville, J. T. Kiehl, and L. E. Buja, 2001: Climates of the twentieth and twenty-first centuries simulated by the NCAR Climate System Model. J. Climate, 14, 485-519.

Daingerfield, L. H., 1921: Kona storms. Mon. Wea. Rev., 49, 327328.

Farrell, B., 1984: Modal and non-modal baroclinic waves. J. Atmos. Sci., 41, 668-673.

Foster, J., M. Bevis, S. Businger, Y.-L. Chen, and Y. Zhang, 2003: The Kau storm (Nov. 2000): Imaging precipitable water using GPS. J. Geophys. Res., 108, 4585, doi:10.1029/2003JD003413.

Fujita, T. T., D. L. Bradbury, and C. F. van Thullenar, 1970: Palm Sunday tornadoes of April 11, 1965. Mon. Wea. Rev., 98, 26-29.

Gall, R. J., 1976: The effects of latent heat release in growing baroclinic waves. J. Atmos. Sci., 33, 1686-1701.

Hebert, P. H., and K. O. Poteat, 1975: A satellite classification technique for subtropical cyclones. NOAA Tech. Memo. NWS SR-83, 87 pp.

Horel, J. D., and J. M. Wallace, 1981: Planetary-scale atmospheric phenomena associated with the Southern Oscillation. Mon. Wea. Rev., 109, 813-829.

Hou, A. Y., 1998: Hadley circulation as a modulator of the extratropical climate. J. Atmos. Sci., 55, 2437-2457.

Junker, N. W., R. S. Schneider, and S. L. Fauver, 1999: A study of heavy rainfall events during the great Midwest flood of 1993. Wea. Forecasting, 14, 701-712.

Kalnay, E. M., and Coauthors, 1996: The NCEP/NCAR 40-Year Reanalysis Project. Bull. Amer. Meteor. Soc., 77, 437-471.

Li, X., and B. Wang, 1994: Barotropic dynamics of the beta gyres and beta drift. J. Atmos. Sci., 51, 746-756.

Mak, M., 1982: On moist quasi-geostrophic baroclinic instability. J. Atmos. Sci., 39, 2028-2037.

Martin, J. E., 1998: On the deformation term in the quasigeostrophic omega equation. Mon. Wea. Rev., 126, 2000-2007.

— , and J. A. Otkin, 2004: The rapid growth and decay of an 
extratropical cyclone over the central Pacific Ocean. Wea. Forecasting, 19, 358-376.

Morrison, I., and S. Businger, 2001: Synoptic structure and evolution of a kona low. Wea. Forecasting, 16, 81-98.

Otkin, J. A., and J. E. Martin, 2004a: A synoptic climatology of the subtropical kona storm. Mon. Wea. Rev., 132, 1502-1517.

$\longrightarrow$, and — 2004b: The large-scale modulation of subtropical cyclogenesis in the central and eastern Pacific Ocean. Mon. Wea. Rev., 132, 1813-1828.

Palmen, E., 1949: On the origin and structure of high level cyclones south of the maximum westserlies. Tellus, 1, 22-31.

Palmer, C. E., 1951: On high-level cyclones originating in the tropics. Eos, Trans. Amer. Geophys. Union, 32, 683-695.

Panofsky, H. A., and W. G. Brier, 1968: Some Applications of Statistics to Meteorology. The Pennsylvania State University, 224 pp.

Quenouille, M. A., 1952: Associated Measurements. Butterworths, $242 \mathrm{pp}$

Ramage, C. S., 1962: The subtropical cyclone. J. Geophys. Res., 67, 1401-1411.

1995: Forecasters guide to tropical meteorology: AWS TR 240 updated. AWS/TR-95/001, Air Weather Service, U.S. Air
Force. 392 pp. [Available from AWSTL, 859 Buchanan St., Scott AFB, IL 62225.]

Riehl, H., 1949: Some aspects of Hawaiian rainfall. Bull. Amer. Meteor. Soc., 30, 167-187.

Roebber, P. J., 1984: Statistical analysis and updated climatology of explosive cyclones. Mon. Wea. Rev., 112, 1577-1589.

Sadler, J. C., 1975: The upper tropospheric circulation over the global tropics. UHMET Rep. 75-05, Dept. of Meteorology, University of Hawaii, Honolulu, HI, 35 pp.

Schroeder, T. A., 1977a: Meteorological analysis of an Oahu flood. Mon. Wea. Rev., 105, 458-468.

_, 1977b: Hawaiian waterspouts and tornadoes. Mon. Wea. Rev., 105, 1163-1170.

Simpson, R. H., 1952: Evolution of the kona storm: A subtropical cyclone. J. Meteor., 9, 24-35.

Sutcliffe, R. C., 1947: A contribution to the problem of development. Quart. J. Roy. Meteor. Soc., 73, 370-383.

Trenberth, K. E., 1978: On the interpretation of the diagnostic quasi-geostrophic omega equation. Mon. Wea. Rev., 106, 131-137.

Wang, B., and X. Li, 1992: The beta drift of three-dimensional vortices: A numerical study. Mon. Wea. Rev., 120, 579-593. 